\title{
Influence of pharmacists expertise on physicians prescription decisions
}

\author{
Mohsen Ali Murshid*, Zurina Mohaidin and Goh Yen Nee \\ Graduate School of Business, Universiti Sains Malaysia, 11800 Penang, Malaysia
}

${ }^{*}$ For correspondence: Email: mohsen092@gmail.com, Tel: +60-19-437-5620

Received:

Revised accepted: 20 April 2016

\begin{abstract}
Purpose: To explore the influence of pharmacist factors on prescription decisions of physicians. Methods: A survey of literature was carried out across online databases and 12 relevant articles were identified. The influence of pharmacist factors on physician prescription decisions was identified in the articles. A conceptual model for investigating pharmacist factors that influence physicians' prescription decisions was then developed.

Results: The main factors identified were pharmacist expertise, pharmacist - physician collaboration, and trust between physician and pharmacist. There was no direct evidence of influence of pharmacist expertise on prescription, but some studies indicated that pharmacist recommendation is in tandem with the prescribing behaviour of physicians. One study reported that pharmacist-physician collaboration positively influenced physicians' prescribing decision, while others found no relationship between these. Conclusion: Existing literature on the influence of pharmacist factors on prescription behaviour of physicians are limited and debatable. There is no consistency in these studies. Moreover, studies that reported a strong connection between the trustworthiness and pharmacist-physician collaboration in drug prescription lack hard evidence.
\end{abstract}

Keywords: Physician prescription behaviour, Pharmacist factor, Collaboration, Trustworthiness

Tropical Journal of Pharmaceutical Research is indexed by Science Citation Index (SciSearch), Scopus, International Pharmaceutical Abstract, Chemical Abstracts, Embase, Index Copernicus, EBSCO, African Index Medicus, JournalSeek, Journal Citation Reports/Science Edition, Directory of Open Access Journals (DOAJ), African Journal Online, Bioline International, Open-J-Gate and Pharmacy Abstracts

\section{INTRODUCTION}

In recent years, the role of the pharmacist has turned from that of a dispenser to that of an influencer [1] and an active participant in decision-making during drug therapy [2].The report of WHO in 1997 highlighted new roles of the pharmacist as "as a caregiver, manager, decision-maker, leader, communicator, lifelong learner, and teacher" [1]. Over the years, the pharmacist's role has expanded to include opinion giving and consultations [3,4]. Nonetheless, these additional roles are often not well developed in developing countries [1] such as Yemen, where pharmacists play a major role in drug prescription [5]. Pharmacists generally provide information relating to drug prescription, which can often be difficult to source in developing nations [2]. Given this role, pharmacists have become important targets for marketing tools of pharmaceutical firms [6].

The expertise of pharmacists makes them the most important source of knowledge on prescription decision-making [2,5,7], especially on drug interactions [1] and the movement of products of various competitors [8,9]. Evidence suggests that physicians are more likely to accept a pharmacist's recommendations regarding the prescription of a particular drug, in 
terms of potency and economic viability $[10,11]$. The advice provided to physicians can be related to the pharmacist's knowledge and experience regarding drug-related issues observed daily in the community [12].

Irrational prescription is a global health problem with the potential of harming both the individual and society [13].This issue makes a logical ground for pharmacists to influence physician prescriptions for improved patient outcome [4]. Unfortunately, poor collaboration between physicians and pharmacists has been recognized as a significant contributor towards inappropriate prescriptions [1]. This underscores the need for improved cooperation for optimal patient care [14]. Evidence suggests that collaboration between physicians and pharmacists improves medication safety and proper prescription [15]. There is good empirical evidence to show that trust is the key driver for improving the physician-pharmacist collaboration, for optimal prescription [11,16-19].

The pharmacist's key role in drug prescription practice often enhances overall patient outcomes $[20,21]$ and the effect of a pharmacist on prescribing practices can undoubtedly be seen often daily in medication dispensing [2]. However, most attempts to explain prescription decision-making have been based on information processing [22], which takes into consideration drug and patient characteristics [23,24] in addition to the influence of marketing promotion techniques [25,26], while overlooking the influence of pharmacist factors [27]. The expertise of pharmacists as well as their collaboration with physicians may be important factors that influence physician's drug prescription decision [12]. This fact is supported by studies which reported that community pharmacists routinely intervene to influence prescription decisions [2,7,19,28,29]. However, only a few studies have directly addressed the pharmacist's ability to make such impacts.

Previous reviews have been relatively discrete, or at most only partially assessed the collaboration between physicians and pharmacists (theoretical models) [16]. Therefore, the objectives of this review are: (1) to search existing literature for an understanding of the pharmacist factors (such as expert power of pharmacist, collaboration and trustworthiness between the pharmacist and physician) that influence physicians' prescription decisions and (2) to explore the theoretical foundations of the effect of pharmacist factors on physician prescribing decisions.

\section{METHODS}

Searches for scientific articles were conducted using GoogleScholar, Sociological Abstracts, ScienceDirect, and PubMed online databases. Searches were restricted to articles published from 2001 to June 2015. Key phrases inputted in search engines included 'factors influencing physician prescribing', 'effect of the pharmacist in prescribing', 'collaboration between physician and pharmacist', 'the influence of physician pharmacist collaboration on prescribing', 'pharmacist recommendation', and 'expert power. A total of 12 articles were finally included in this review and these were reports of studies conducted in the USA (five articles), Netherlands (one article), Australia (three articles), France (one article), Nigeria (one article) and Ireland (one article).

\section{RESULTS}

Table 1 shows characteristics of studies included in this review. A careful review of the content of the research articles reveals three main pharmacist factors found to be influencing physician decision to prescribe drugs: pharmacist expert power, pharmacist - physician collaboration, and trust between the physician and the pharmacist.

\section{Expert power of pharmacist and prescribing decision}

The expertise of the pharmacist has its roots in the social power theory. This theory originated from French and Raven [33] who tried to explain the sources of power individuals use to influence others. Power itself is known as the potential for influence [34]. Social power is the ability of a person or group to cause another person or group to change their attitudes or behaviours in the direction intended by the influencer [35]. French and Raven [33] summarized five bases of the sources of the social power in which an individual may have power like expert power, reward power, referent power, legitimate power, and coercive power. Expert power is based on the "influence's perception that the influencer has some special knowledge, information, or skills in a relevant area" [35]. It may be recognized that a pharmacist possesses itemized knowledge, information, skill, confidence, and power to control outcomes of the drug $[1,36]$. 
Table 1: Characteristics of studies reviewed

\begin{tabular}{lcll}
\hline Theme of research & $\begin{array}{c}\text { Author } \\
\text { (Country) }\end{array}$ & Study design & Results \\
$\begin{array}{l}\text { Develop and validate the } \\
\text { collaboration instrument for } \\
\text { pharmacist }\end{array}$ & $\begin{array}{c}\text { Van et al [30] } \\
\text { (Australia) }\end{array}$ & $\begin{array}{l}\text { Cross-sectional study utilized a } \\
\text { questionnaire mailed to stratified } \\
\text { sampling of 1215 pharmacists }\end{array}$ & $\begin{array}{l}\text { Communication and trust are the } \\
\text { strongest influence on pharmacist - } \\
\text { physician collaboration }\end{array}$ \\
$\begin{array}{l}\text { Develop and validate the } \\
\text { collaboration instrument for } \\
\text { physician }\end{array}$ & $\begin{array}{l}\text { Van et al } \\
\text { (Australia) }\end{array}$ & $\begin{array}{l}\text { Cross-sectional study utilised a } \\
\text { questionnaire mailed to stratified } \\
\text { sampling of1145 general } \\
\text { practitioners(GPs) }\end{array}$ & $\begin{array}{l}\text { Interactional and practitioner } \\
\text { determinants and the role of the } \\
\text { pharmacist in medication were two } \\
\text { predictors physician -pharmacist }\end{array}$ \\
$\begin{array}{l}\text { Physician beliefs and } \\
\text { attitudes toward } \\
\text { collaboration with } \\
\text { community pharmacists }\end{array}$ & $\begin{array}{c}\text { Kucukarslan et } \\
\text { al [18] } \\
\text { (USA) }\end{array}$ & $\begin{array}{l}\text { Cross-sectional study utilised a } \\
\text { questionnaire mailed to 1109 } \\
\text { specialists' physicians. }\end{array}$ & $\begin{array}{l}\text { Physician- pharmacist } \\
\text { collaboration improves physician } \\
\text { prescribing }\end{array}$
\end{tabular}
Impact of the cooperation with pharmacists on prescribing

Review on the collaboration between physician and pharmacist

Factors that influence prescribing decisions

Pharmacists willingness to influence a physician's decision

Exploring GPspharmacist relationship

The expectations of GPs and pharmacists around collaboration

Dey et al

[31]

(Australia)

Doucett et al [3] (USA) between pharmacists and physicians,

Develop and validate the collaboration instrument for physicians Physician-pharmacist collaborative role in patient management (USA)

Yilshal et al [32] (Nigeria)
Muijrers et al Cross-sectional survey of 1434

(Netherland )

\begin{tabular}{|c|c|}
\hline $\begin{array}{l}\text { Bardet et al } \\
\quad[16] \\
\text { (France) }\end{array}$ & $\begin{array}{l}\text { An extensive literature search } \\
\text { from } 1990 \text { to June } 2013 \text { were } \\
\text { conducted }\end{array}$ \\
\hline
\end{tabular}

Schumock et al Cross-sectional study utilized a [10] telephone survey administered to (USA)

Basak et al [4]

(USA)

Moore et al [19] (Ireland) 150physicians, pharmacists and formulary committee members in community hospitals

Cross-sectional study utilised an electronic link questionnaire administered to 243 pharmacists (who in a hospital pharmacy setting)

Cross-sectional study utilised a questionnaire mailed to 500 GPs and 335 community pharmacists

Semi-structured interview through purposive sampling was conducted with 17 GPs and 7 community pharmacists

Cross-sectional study utilised a questionnaire mailed to a sample of 321 pharmacists

Zillich et al [17] Cross- sectional survey of a random sample of 1000 physicians was conducted. Cross-sectional study utilised a self-administrated questionnaire administered to 32 pharmacists, 60 physicians and 200 patients
The results show no measurable effects between physicians pharmacist cooperation and quality of prescribing Interactional determinants such as trust and communication are the main drivers of physicianspharmacist collaboration Pharmacist recommendations influence the physician prescribing decisions

Pharmacist expert power modulates the willingness of the pharmacist to influence the physician

The results suggested that $14 \%$ of pharmacists and $9 \%$ of physician felt that pharmacists have an influence on the prescribing behavior of a physician

Results showed a minimal collaboration between physicians and pharmacist in terms of the extent to which they engaged decision-making Trustworthiness is the factor associated with the development of the pharmacist-physician collaboration

Trustworthiness was positively associated with physicianpharmacist collaboration Trustworthiness is a key factor that promotes physicians pharmacist collaboration Interactional determinants' such as trust and communication was the strongest predictor of collaboration 
In practice, pharmacists have been shown to have the expert power source such as knowledge of drugs [1] and information power (i.e., present information or evidence about drugs) when attempting to influence prescriptions [4]. A vast body of the research supports this perspective $[4,12,37]$. For example, the physician may have a little knowledge when it comes to decision - making on new drugs. Thus, some of them rely on advice or recommendation from pharmacists who have better information of on drugs [2,11]. Therefore, it is logical to assume that physicians readily comply with the recommendations of pharmacists relating to drug information because of their expertise.

According to social power theory, during the physician-pharmacist interaction involving drugs, pharmacists' perception that they have potential to influence the physicians may likely lead them to exert power in various strategic forms. Qualitative studies have documented that pharmacists in some cases use a number of strategies to influence physicians' prescription decision, such as offering a certain percentage from the drug sales, obtaining clinic rental payment, and allowing the sale of their free samples [38]. One study revealed that most physicians expect pharmacists to be experts in drug prescribing and thus to serve as guides in the appropriate use of drugs [39]. Another study also analyzed the current status of pharmacist's influence on drug prescription and found that such influence can be seen daily in any conceivable situation [2].

It has also been found that $34 \%$ of physicians consult pharmacists before prescribing drugs [37]. The advice provided to physicians by the pharmacist may be based on the pharmacist's expertise and drug-related problems seen in the pharmacy on a day-to-day basis [12]. A crosssectional study on general practitioners (GPs)pharmacist relationship discovered that $37 \%$ of GPs and $43 \%$ of pharmacists accept that communication between the professionals was very good, while $14 \%$ of GPs and $9 \%$ of pharmacists felt that pharmacists have a significant influence on the prescribing behaviour of physicians [19]. Out three cross-sectional studies, one showed that recommendations from pharmacists can improve the quality of prescriptions. Physicians are often likely to accept these recommendations in some cases to resolve drug-related problems [11]. Many of these physicians implemented or attempted to implement $72.3 \%$ of pharmacist recommenddations [40]. Pharmacist recommendations have also been reported to influence prescription of the physician in a study that investigated the opinions of physicians, formulary committee members and pharmacists [10].

Only one of the studies reviewed was conducted on pharmacist expert power, as defined by Basak et al [4]; the study examined the role of perceived impact on relationship quality on the willingness of hospital pharmacist to influence prescribing decisions based on off-label drugs. It concluded that pharmacist expert relative power modulates the willingness of a pharmacist to influence the physician prescribing. In general, the effect of pharmacist expert power on the physician prescribing has not been tested, but, it seems reasonable to assume that to a greater or lesser extent, pharmacist recommendation at the time of prescribing by physician often exists.

\section{Pharmacist - physician collaboration and prescribing decision}

The roles of the physician and pharmacist in the prescribing process are complementary [11]. One study suggested that collaboration between physicians and pharmacists is beneficial for better prescriptions [40]. In practice, cooperation between physicians and pharmacists emerged as a key influence on prescribing behavior $[12,19]$. As a result, governments and organizations of health care around the world invest significant resources to improving collaboration between these professionals [41].

Zwarenstein et al [41] defined collaboration as "the process in which different professional groups work together to positively impact healthcare." This means that strong working relationships between pharmacists and physicians are needed to optimize patient care [21]. In other words, prescription decision making is an outcome of collaboration between the physician and the pharmacist [42]. One study revealed that the main reason for collaboration between physician and pharmacist was about prescriptions [43].

In order to better understand the physicianpharmacist collaboration, it is reasonable to turn to the model of the collaboration working relationship (CWR). CWR model was derived from previous models of business relationships, interpersonal relationships, cooperation care from physician-pharmacist relationship [44] and trust between professionals [16]. CWR was first developed in 2001 by McDonough and Doucette [45] re-modelled by Bradley et al [46] and 
recently by Van et al [15] who established Attitudes Toward Collaboration Instrument for general physicians (ATCI-GP) model.

CWR also was developed by Zillich et al [17], who proposed that three constructs: participant characteristics, context characteristics, and exchange characteristics affect collaboration between physicians and pharmacists. In this model, exchange characteristics consisted of three constructs: role specification, relationship initiation and trustworthiness. Trustworthiness involved both the degree of bidirectional communication and the medical practitioner's credibility and reliability.

ATCI-GP model [15] was derived from Zillich et al model [17]. The model shows the factors that influence physician-pharmacist collaboration from the pharmacist's perspective in the provision of healthcare in Australia. The factors include interactive determinants such as communication, trust, a willingness to work together, and mutual respect. These factors directly influence pharmacist-physician collaboration. An important feature of this model is its suitability for measurement from physician to pharmacist. The model also may be a useful tool in determining the extent of collaboration in current practice and will allow for empirical assessment of interventions targeted at enhancing pharmacist-physician collaboration.

This paper focuses on trustworthiness as a moderator of the relationship between pharmacist-physician collaboration and physician prescription based on this model.

There is a wide range of viewpoints amongst academics about pharmacist - physician collaboration. Physicians claim that quality of prescription is dependent on pharmacist collaboration and its synergistic effects [12]. Further support for this perception is given by the work of Yilshal \& Noel [32], who noted that physician-pharmacist collaboration improves prescription quality through increase in the efficiency and safety of drugs. Five studies reported that when pharmacists have successfully collaborated with physicians in the drug therapy processes, patient outcomes and physician prescribing behaviour improved [18,32,47-49]. One study using statistical tests and multiple regression found a positive effect of the collaboration of pharmacist on physician prescription [18].
In contrast, three studies had mixed results: one study found no association between quality of prescription and cooperation of pharmacists with physicians [12]. It reported a gap between the potential and actual influence of the pharmacist cooperation on prescription. This study recommended further research into the optimal form of cooperation between physicians and pharmacists. A second study examined the expectations, experiences and perceptions of physicians and pharmacists about collaboration in the primary care setting. It found that there is a minimal collaboration between the physician and pharmacist [31]. A third study investigated the opinions of physicians and pharmacist on physician -pharmacist collaboration in patient therapy. The results indicated that no statistical difference on the need to encourage collaboration among respondents [32]. Furthermore, the respondents agreed that physician-pharmacist collaboration is necessary and should be encouraged.

\section{Trustworthiness between physician and pharmacist and prescribing decision}

Trustworthiness in this research is defined as a physician's ability to trust a pharmacist's word and expertise [17]. Trustworthiness is considered the main driver that improves and supports physician-pharmacist relationship [32]. A 2015 review concluded that trustworthiness was an important factor in enhancing collaborative relationships between physicians and pharmacists [16]. Several studies indicated that trustworthiness strongly impacts on pharmacistphysician collaboration, which in turn positively influences physician prescribing behaviour $[3,17,44,46,50]$.

Other studies provide additional support for the influence of trustworthiness on pharmacistphysician collaboration $[3,15,17]$. One of these conducted by mailed survey showed that trustworthiness was positively associated with physician-pharmacist collaboration [17]. A second study in the same year investigated the factors associated with pharmacist-physician collaboration at baseline and at 3 months. The results indicated that trustworthiness was the strongest predictor of physician-pharmacist collaboration at these points [3]. A third and more recent, cross-sectional study found that trustworthiness (such as communication and trust) was the strongest factors influencing the pharmacist - physician collaboration [15]. 
The collaboration of the pharmacist was found to have significant influence on physician prescribing behaviour. However, the magnitudes of effects reported vary considerably and in some cases even conflict. Thus a systematic research on the conditions under which this link is strengthened is lacking. The basic rationale for studying trustworthiness as moderator of this link is that the level of pharmacist-physician collaboration in prescribing practice depends on trustworthiness between professionals.

For example, high level of trustworthiness ensures more collaboration because it stimulates cooperation between physician and pharmacist. There is a large empirical evidence showing that trustworthiness improves the collaboration process between physician and pharmacists and stimulates interaction, which in turn positively influences physician prescribing behaviour $[3,17,18,31,50]$. Since pharmacist-physician collaboration can affect prescription only if the physician considers it reliable, the level of physician's trust in the pharmacist moderates the link between collaboration and prescribing.

\section{DISCUSSION}

The evidence base for pharmacist factor influence on prescription by physicians is narrow, and based mainly on cross-sectional, selfcompleted questionnaire studies, surveys and interviews. For example, studies exclusively based on pharmacist expert power are scanty, although available evidence suggests that pharmacist can influence physician prescribing behaviour $[1,2,7,28,29,38]$. Some studies have shown that the influence of pharmacist-physician collaboration on prescribing behaviour is trivial and inconclusive. Moreover, the moderating impact of trustworthiness on the effect of pharmacist-physician collaboration upon prescribing remains unclear.

The influence of the pharmacist expert power on physician prescribing decision has not been reported in detail. This review found no direct evidence of the influence pharmacist expert power on prescribing attitude, but some studies indicate that pharmacists' recommendation or consultation is in tandem with the prescribing behaviour of physicians [10-12]. Social power theory provides theoretical support for this relationship. According to this theory, the key mechanism leading to a change in behaviour is that one person $(B)$ has the expert power to influence the other person $(A)$ in order to change his or her behaviour. Logically, it is expected that a pharmacist will take this active role in influencing prescription behaviour since physicians are likely to rely on advice or recommendations from pharmacists who have more information, knowledge, confidence and power to control $[4,12,37]$.

Theoretically, pharmacist - physician collaboration may improve the physician prescribing decisions and thus enhance patient outcome. However, some of studies have shown that the influence of pharmacist-physician collaboration on prescribing behaviour is insignificant and unconvincing. For example, some studies found no relationship between these two [12], while others reported a small effect [18]. This may be due to the fact that the current level of cooperation between the physician and pharmacist in the prescribing process is weak [31]. Moreover, these studies are narrowly focused and so may be regarded as partial assessments of the relationship between pharmacist - physician collaboration and prescribing quality.

On the other hand, given the reported weak relationship between the pharmacist collaboration and physician prescribing behaviour, this paper posits that trustworthiness is a potential tool for strengthening this collaboration. Thus, the response of physicians to pharmacist intervention possibly modulates their prescribing behaviour. The review proposes that trustworthiness has a bearing on the influence of pharmacist - physician collaboration on physician prescribing behaviour $[3,15,17]$.

\section{Proposed model for further research}

A theoretical model of pharmacist - physician interplay on prescription based on the pharmacist factors enumerated in the present review, is shown in Figure 1. The proposal model has four major constructs. The model includes factors discussed in this review such as pharmacist expert power and pharmacist - physician collaboration that may affect directly physician decision to prescribe drugs. The theoretical 


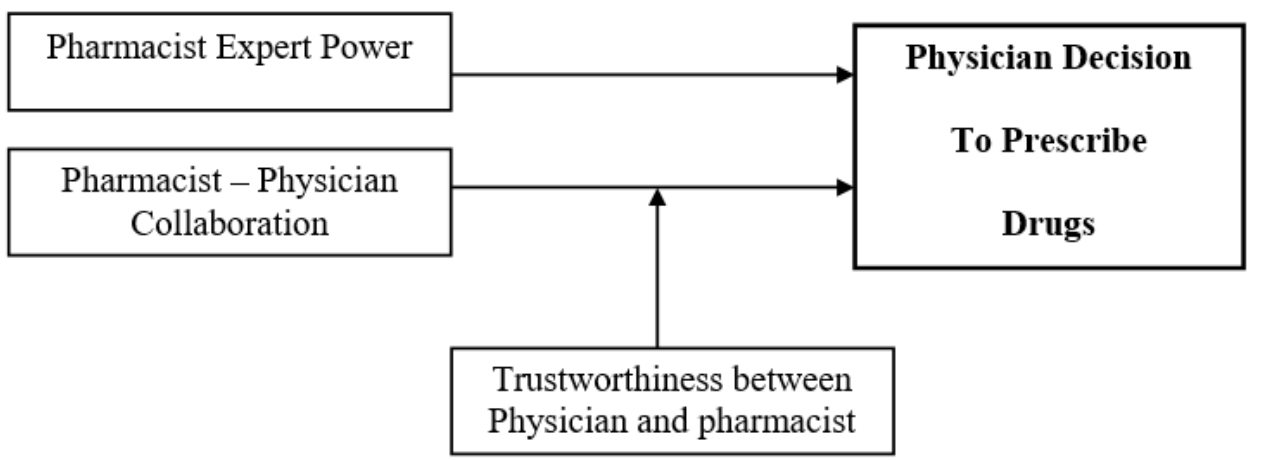

Figure 1: Proposed model of pharmacist - physician collaboration in prescription

model is also an approach towards recognizing trustworthiness as a variable that may moderate the relationship between pharmacist-physician collaboration and prescribing behaviour. Nonetheless, the study recommends further research on the influence of each factor on physician prescribing behaviour and an evaluation of the proposed model and moderating variables.

\section{CONCLUSION}

The body of evidence on the pharmacist factors that influence physician's decision to prescribe drugs is relatively small. In theory, pharmacist's expertise and collaboration with physicians affect prescription decision and may also influence patient health by improving the quality and rational of prescription. However, in this review, we have found little evidence to support this. There is still a need to understand in relation to how pharmacist factors affect physician prescription behaviour.

One clear finding from this review is the absence of evidence on impact of pharmacist - physician collaboration on prescription behaviour. Some of the studies argue that poor professional collaboration between the physician and pharmacist leads to increase in irrational prescriptions. This should be of concern for policy makers and managers of health care. The present review contributes to resolving the debate on the ways pharmacist - physician collaboration affect prescribing behaviour. More specifically, this research investigates the level to which the effects of pharmacist - physician collaboration on physician decision making may depend upon trustworthiness between the two professionals. Further empirical research to examine this construct based on proposed model is needed.

\section{DECLARATIONS}

\section{Conflict of Interest}

No conflict of interest associated with this work.

\section{Contribution of Authors}

The authors declare that this work was done by the authors named in this article and all liabilities pertaining to claims relating to the content of this article will be borne by them.

\section{REFERENCES}

1. Taher, A., Stuart, E. W., Hegazy, I. The pharmacist's role in the Egyptian pharmaceutical market. International Journal of Pharmaceutical and Healthcare Marketing 2012; 6(2):140-155.

2. Nissen, L. Current status of pharmacist influences on prescribing of medicines. American Journal of HealthSystem Pharmacy 2009; 66(5 Supp/ 3): 29-34.

3. Doucette, W. R., Nevins, J., \& McDonough, R. P. Factors affecting collaborative care between pharmacists and physicians. Research in Social and Administrative Pharmacy 2005; 1: 565-578.

4. Basak, R., Bentley, J. P., Mccaffrey, D. J., Bouldin, A. S., \& Banahan, B. F.The role of perceived impact on relationship quality in pharmacists ' willingness to influence indication-based off-label prescribing decisions. Social Science \& Medicine 2015; 132: $181-$ 189.

5. Al-worafi, Y. M. Pharmacy practice and its challenges in Yemen. Australasian Medical Journal [AMJ, 2014; 7(1): 17-23.

6. Kim, W. J., \& King, K. W. Product Category Effects on External Search for Prescription and Nonprescription Drugs. Journal of Advertising 2009; 38(January): 5-20.

7. Albadr, Y., \& Khan, T. M. Factors influencing community pharmacist decision to dispense generic or branded medicines; Eastern Province, Alahsa, Saudi Arabia. Saudi Pharmaceutical Journal 2014; 7(002)1-4. 
8. Srivastava, V., Handa, M., \& Vohra, a. Pharmaceutical retailers and promotion by pharmaceutical companies in India. Journal of Medical Marketing: Device, Diagnostic and Pharmaceutical Marketing 2014; 14(2-3): 74-80.

9. Hussain, A., \& Ibrahim, M. I. Perceptions of dispensers regarding dispensing practices in Pakistan: $A$ qualitative study. Tropical Journal of Pharmaceutical Research 2011; 10(2): 117-123.

10. Schumock, G. T., Walton, S. M., Park, H. Y., Nutescu, E. a., Blackburn, J. C., Finley, J. M., \& Lewis, R. K. Factors that Influence Prescribing Decisions. Annals of Pharmacotherapy 2004; 38(4): 557-562.

11. Rigby, D. Collaboration between doctors and pharmacists in the community. Australian Prescriber 2011; 23(6): 191-193.

12. Muijrers, P. E. M., Grol, R. P. T. M., Sijbrandij, J., Janknegt, R., \& Knottnerus, J. A. Differences in prescribing between GPs. The impact of the cooperation with pharmacists and impact of visits from pharmaceutical industry representatives. Family Practice 2005; 22(6): 624-630.

13. Delirrad, M., Javaezi, M., Majdi, L., \& Sadigh-Rad, L. Comparison of prescribing indicators of academic versus non-academic specialist physicians in Urmia, Iran. Journal of Research in Pharmacy Practice 2015; 4(2): 45

14. Gokcekus, L., Toklu, H. Z., Demirdamar, R., \& Gumusel, $B$. Dispensing practice in the community pharmacies in the Turkish Republic of Northern Cyprus. International Journal of Clinical Pharmacy 2012; 34(2): 312-24.

15. Van, C., Costa, D., Mitchell, B., Abbott, P., \& Krass, I. Development and validation of a measure and a model of general practitioner attitudes toward collaboration with pharmacists. Research in Social and Administrative Pharmacy 2013; 9(6): 688-699.

16. Bardet, J., Pharm, D., Pharm, M., \& Bedouch, P. Physicians and community pharmacists collaboration in primary care: A review of specific models. Research in Social and Administrative Pharmacy 2015; 33: 1-21.

17. Zillich, A. J., Doucette, W. R., Carter, B. L., \& Kreiter, C. $D$. Development and Initial Validation of an Instrument to Measure Physician - Pharmacist Collaboration from the Physician Perspective. Value in Health 2005; 8(1): 10 14.

18. Kucukarslan, S., Lai, S., Dong, Y., Al-Bassam, N., \& Kim, K. Physician beliefs and attitudes toward collaboration with community pharmacists. Research in Social \& Administrative Pharmacy: RSAP, 2011; 7(3): 224-32.

19. Moore, T., Kennedy, J., \& McCarthy, S. Exploring the General Practitioner-pharmacist relationship in the community setting in Ireland. The International Journal of Pharmacy Practice 2014; 22(5): 327-34.

20. Al-rukban, M. O., \& Rizvi, M. R. Pharmacist 's Knowledge, Attitude and Practices towards Written Prescription in Dispensing and Substitution of Drugs in Riyadh 2014. Majmaah J HIth Sci.2014; 2(2): 28-34.

21. Kelly, D. V, Bishop, L., Young, S., Hawboldt, J., Phillips, L., \& Keough, T. M. Pharmacist and physician views on collaborative practice: Findings from the community pharmaceutical care project. Canadian Pharmacists Journal 2013; 146: 218-26.

22. Afriyie, D. K., Amponsah, S. K., Antwi, R., Nyoagbe, S. Y., \& Bugyei, K. A. Prescribing trend of antimalarial drugs at the Ghana Police Hospital. The Journal of Infection in Developing Countries 2015; 9(04).

23. Al-Areefi, M. A., Hassali, M. A., \& Ibrahim, M. I. B. M. Physicians' perceptions of medical representative visits in Yemen: a qualitative study. BMC Health Services Research 2013; 13(1): 331.

24. Patel-Dovlatabadi, P. Factors associated with physicians' prescribing behavior for treatment of influenza in the USA. International Journal of Pharmaceutical and Healthcare Marketing 2014; 8(1): 27-46.

25. Gonul, F. F., Carter, F., Petrova, E., \& Srinivasan, K. Promotion of Prescription Drugs and Its Impact on Physicians' Choice. Journal of Marketing 2001; 65(July); 79-90.

26. Ladeira, W., Dalmoro, M., Eduardo Maehler, A., \& Falcão Araujo, C. Drug prescription practices in Brazil: a structural equation model. International Journal of Pharmaceutical and Healthcare Marketing 2011; 5(4); 262-278.

27. Kasliwal, N. A Study of Psychosocial Factors on Doctors Prescribing Behaviour - An Empirical Study in India. IOSR Journal of Business and Management 2013; 13(2): 05-10.

28. Florentinus, S. R., Van Hulten, R., Kloth, M. E. M., Heerdink, E. R., Griens, a. M. G. F., Leufkens, H. G. M., \& Groenewegen, P. P. The effect of pharmacotherapy audit meetings on early new drug prescribing by general practitioners. Annals of Pharmacotherapy 2007; 41(2): 319-324.

29. Gallagher, R. M., \& Gallagher, H. C. Improving the working relationship between doctors and pharmacists: Is inter-professional education the answer? Advances in Health Sciences Education 2012; 17(2): 247-257.

30. Van C., Costa, D., Abbott, P., Mitchell, B., \& Krass, I. Community pharmacist attitudes towards collaboration with general practitioners: development and validation of a measure and a model. BMC Health Services Research 2012; 12(1): 320.

31. Dey, R. M., De Vries, M. J. W., \& Bosnic-Anticevich, S. Collaboration in chronic care: Unpacking the relationship of pharmacists and general medical practitioners in primary care. International Journal of Pharmacy Practice 2011; 19: 21-29.

32. Yilshal Fabian, A., \& Noel N, W. Doctor-pharmacist collaborative role in patient management: perception of patients, doctors and pharmacists. West African Journal of Pharmacy 2014; 25: 55-67.

33. French JRP, Raven B. The bases of social power. In Cartwright $D$ (Ed.). Studies in Social Power, University of Michigan Press, Ann Arbor, MI Raven, B; 1959.

34. Raven, H. Conceptualizing and Measuring a Power interaction Model of Interpersonal Influence1. J. Appl. Soc. Psychol. 1998; 28(4): 307-332.

Trop J Pharm Res, July 2016; 15(7): 1556 
35. Busch, $P$ \& Wilson, $D$. "An experimental analysis of a salesman's expert and referent bases of social power in the buyer-seller dyad." Journal of Marketing Research 1976; 13(1); 3-11.

36. Wheeler, A., Crump, K., Lee, M., Li, L., Patel, A., Yang, $R$, Jensen, $M$. Collaborative prescribing: $A$ qualitative exploration of a role for pharmacists in mental health. Research in Social and Administrative Pharmacy 2012; 8: 179-192.

37. Neyaz, Y., Qureshi, N. A., Khoja, T., Magzoub, M. A., Haycox, A., \& Walley, T. Physicians' medication prescribing in primary care in Riyadh city, Saudi Arabia. Literature review, part 1: variations in drug prescribing. Eastern Mediterranean Health Journal 2011; 17(2).

38. Al-Hamdi, a. Y., Hassali, M. a. a., \& Ibrahim, M. I. M. Impact of pharmaceutical promotion on healthcare professional's practices and behaviour: Views from general practitioners, medicine dispensers and medical representatives in Yemen. Journal of Medical Marketing: Device, Diagnostic and Pharmaceutical Marketing 2012, 12(4); 240-246.

39. Zaidan, M., Singh, R., Wazaify, M., \& Tahaineh, L. Physicians' perceptions, expectations, and experience with pharmacists at Hamad Medical Corporation in Qatar. Journal of Multidisciplinary Healthcare 2011; 4: 85-90.

40. Sellors, J., Kaczorowski, J., Sellors, C., Dolovich, L., Woodward, C., Willan, A, Poston, J. elderly patients. Can Med Assoc J 2003; (1): 17-12.

41. Zwarenstein, M., Goldman, J., \& Reeves, S. Interprofessional collaboration : effects of practice-based interventions on professional practice and health care outcomes (Review). JohnWiley \& Sons, Ltd 2009; (3).

42. Edwards, I. A. N. E., Dip, G., Ortho, P., Ones, M. A. R. K. J., \& Manip, M. (2004). What is Collaborative Reasoning? Advances in Physiotherapy 2004; 6: 70 83.

43. Io, U. M., Hu, H., Oi, C., \& Ung, L. Physicians' and Pharmacists' Experience and Expectations of the Roles of Pharmacists : Insights into Hospital Setting in Macau. Tropical Journal of Pharmaceutical Research 2013; 12(December): 1077-1085.

44. Snyder, M. E., Zillich, A. J., Primack, B. A., Rice, K. R., Somma McGivney, M. A., Pringle, J. L., \& Smith, R. B. Exploring successful community pharmacist-physician collaborative working relationships using mixed methods. Research in Social \& Administrative Pharmacy: RSAP, 2010;6(4):307-23.

45. McDonough, R. P., \& Doucette, W. R. Developing collaborative working relationships between pharmacists and physicians. Continuing program on Value-Added Services for pharmacists. J Am Pharm Assoc 2001;41(202): 682-92

46. Bradley, F., Ashcroft, D. M., \& Noyce, P. R. Integration and differentiation: $A$ conceptual model of general practitioner and community pharmacist collaboration. Research in Social and Administrative Pharmacy 2012; 8(1); 36-46.

47. Makowsky, M. J., Schindel, T. J., Rosenthal, M., Campbell, K., Tsuyuki, R. T., \& Madill, H. M. Collaboration between pharmacists, physicians and nurse practitioners: a qualitative investigation of working relationships in the inpatient medical setting. Journal of Interprofessional Care 2009; 23(March):169-184.

48. Magzoub, M. A., Neyaz, Y., Khoja, T., Qureshi, N. A., Haycox, A., \& Walley, T. Determinants of physicians , medication prescribing behaviour in primary care in Riyadh city, Saudi Arabia. Eastern Mediterranean Health Journal 2011; 17(2).

49. McKinnon, A., \& Jorgenson, D. Pharmacist and physician collaborative prescribing: For medication renewals within a primary health centre. Canadian Family Physician 2009; 55(12).

50. Liu, Y., Doucette, W. R., \& Farris, K. B. Examining the development of pharmacist-physician collaboration over 3 months. Research in Social \& Administrative Pharmacy: RSAP 2010; 6(4): 324-33. 